\title{
Account
}

\section{Baylis-Hillman Reaction and Chemical Transformations of Baylis-Hillman Adducts}

\author{
Ka Young Lee, Saravanan Gowrisankar, and Jae Nyoung Kim* \\ Department of Chemistry and Institute of Basic Science, Chonnam National University, Gwangju 500-757, Korea \\ "E-mail:kimjn@chonnam.ac.kr \\ Received June 15, 2005
}

\begin{abstract}
Carbon-carbon single bond-forming reaction is the most useful and fundamental reaction in organic synthesis. Most of the basic carbon-carbon single bond-forming reactions, thus, developed in the past. In these respects, conceptually new C-C bond formation reaction can be highlighted. The Baylis-Hillman reaction was found at the early 1970's. However, extensive studies on this highly potential reaction were started only before 15 years. This review has been written to shed more lights to the importance of Baylis-Hillman reaction. We have focused mainly on the reaction mechanism, conceptually related reactions, and chemical transformations of the Baylis-Hillman adducts.
\end{abstract}

Key Words : Baylis-Hillman reaction, Baylis-Hillman adducts, Chemical transformations

\section{Introduction}

The Baylis-Hillman (BH) reaction, also known as the Morita-Baylis-Hillman reaction, is an attractive method for forming carbon-carbon single bond and yields highly functionalized products with a new stereocenter, so called as Baylis-Hillman adducts. ${ }^{1}$ There were no outstanding investigations during almost two decades since 1972 after the initial finding of $\mathrm{BH}$ reaction. At the middle of the 1990's Basavaiah and Kim group independently started extensive investigations of this useful reaction. Later, many research groups reported tremendous informative and useful improvements on the $\mathrm{BH}$ chemistry. The number of published papers involving the $\mathrm{BH}$ reaction is increasing dramatically recently. In the past, most attention was focused on the finding of new electrophilic substrates or on the rate improvements of the reaction. In the $\mathrm{BH}$ chemistry nowadays, the most active areas can be divided into three categories: (1) improvement of reaction rate and yields of products, (2) control of the asymmetric center of $\mathrm{BH}$ adducts, and (3) development of a variety of chemical transformations with $\mathrm{BH}$ adducts.

\section{Findings of Baylis-Hillman Reaction}

In 1963 Rauhut and Currier disclosed a patent describing a phosphine-catalyzed dimerization of activated alkenes (Scheme 1). ${ }^{2}$ As shown in Scheme 1, this reaction involved a reversible phosphine conjugate addition to the activated
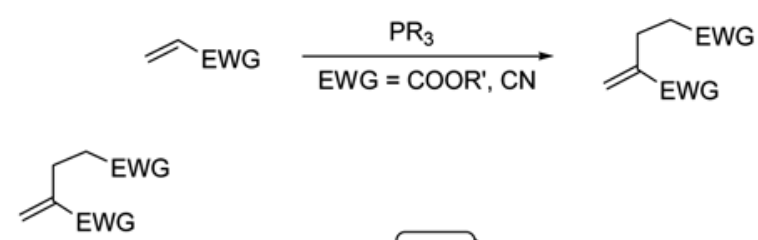

EWG
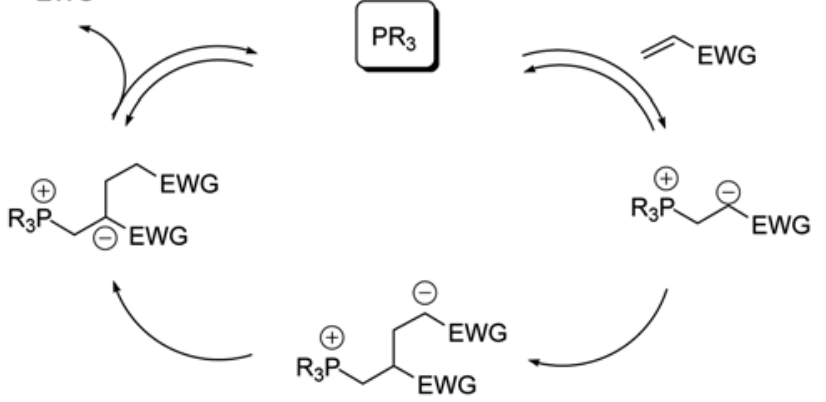

Scheme 1. The Rauhut-Currier dimerization of activated alkenes.
Ka Young Lee was born in 1977 in Gwangju, Korea. She received her B. S. (2000) and M. S. (2002) degrees from Chonnam National University. She is currently a $\mathrm{Ph}$. D. student focusing on the chemical transformations of the Baylis-Hillman adducts. She is a recipient of scholarships from Seoam Scholarship Foundation since 2003.

Saravanan Gowrisankar was born in 1977 in Tamilnadu, India. He received his B. S. (1998) from Erode Arts College and M. S. (2001) from R. K. M. Vivekananda College. After spending 2 years at Indian Institute of Technology at Kanpur, he moved to Korea in 2003. He is currently a Ph. D. student focusing on the chemical transformations of the Baylis-Hillman adducts containing multiple bond.

Jae Nyoung Kim was born in 1960 in Seoul, Korea. He received his B. S. degree from Seoul National University in 1984, his M. S. in 1986 and Ph. D in 1992 from Korea Advanced Institute of Science and Technology. After spending 10 years as a senior research scientist at Korea Research Institute of Chemical Technology (1984-1994), he joined Chonnam National University as an assistant professor of organic chemistry in 1995. Currently he is a full professor of organic chemistry at the same university. He is a recipient of the Award for the Advancement of Science (2000) from Korean Chemical Society. 
alkene, followed by a Michael reaction of the enolate with the second activated alkene. A prototropic shift followed by an elimination process forms the dimer and releases the phosphine.

The zwitterionic phosphonium Michael adducts can be trapped with other electrophiles such as aldehydes. The Rauhut-Currier dimerization of activated alkenes might become the clue to the advent of the Morita's finding. The Morita-Baylis-Hillman reaction is an atom economical coupling of an activated alkene and an aldehyde in the presence of a nucleophilic catalyst. The reaction was first discovered and reported by Morita and co-workers in $1968^{3}$ and by Baylis and Hillman in $1972 .{ }^{4}$ The nucleophilic catalyst employed by Morita was tricyclohexylphosphine, while Baylis and Hillman used tertiary amines such as DABCO (Scheme 2). Activated alkenes include acrylic esters, acrylonitrile, vinyl ketones, phenyl vinyl sulfone, phenyl vinyl sulfonate ester, vinyl phosphonate and acrolein. ${ }^{1}$

Krische $^{5}$ and Roush ${ }^{6}$ groups have studied extensively the intramolecular version of the Rauhut-Currier reaction independently (Scheme 3). The intramolecular variant of the Morita-Baylis-Hillman reaction was reported first by Frater

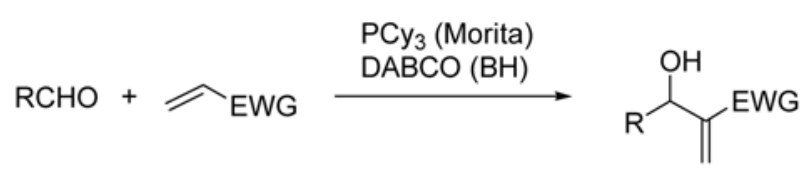

Scheme 2. Morita and Baylis-Hillman reactions.

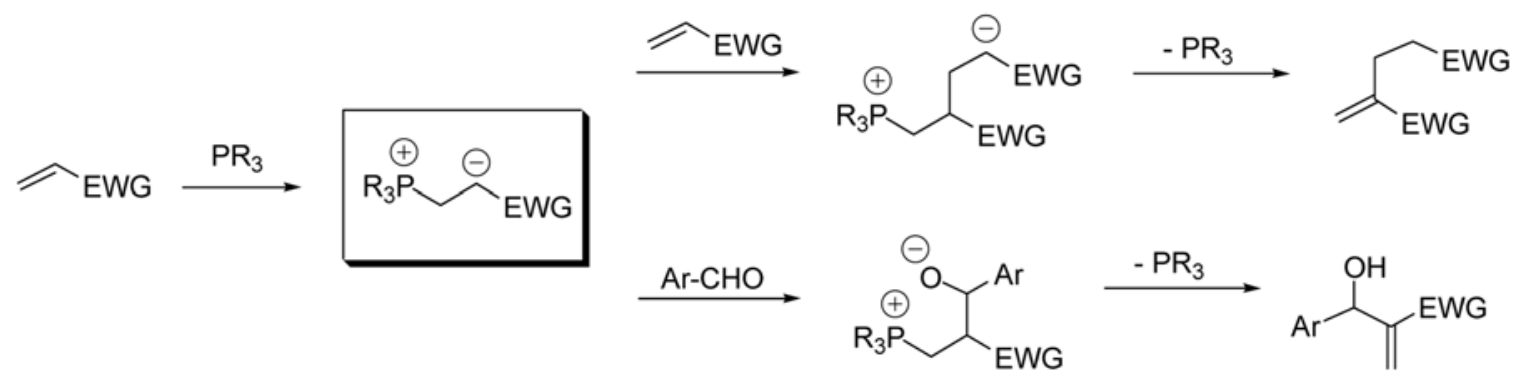

Scheme 5. Comparison of $\mathrm{PR}_{3}$-catalyzed $\mathrm{BH}$ reaction and Rauhut-Currier dimerization.

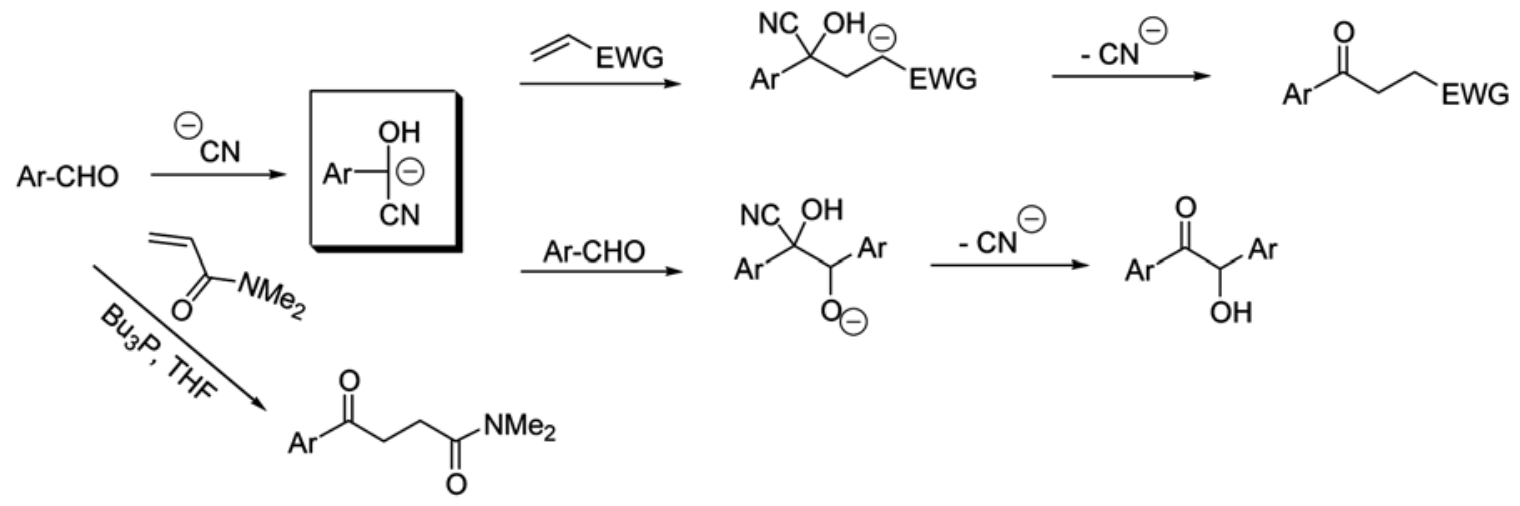

Scheme 6. Comparison of cyanide ion-catalyzed Stetter reaction and benzoin condensation. 
the first tributylphosphine-catalyzed Stetter reaction as shown in Scheme $6 .^{8}$

\section{Reaction Mechanism of the Baylis-Hillman Reaction}

In 1983, Hoffmann and Rabe suggested the first arrowpushing mechanism for the Baylis-Hillman reaction. ${ }^{9}$ Later Hill and Isaacs reported a mechanism (Scheme 7), which was accepted as the most probable one until recently. ${ }^{10}$ However, very recently McQuade and co-workers suggested a new mechanism based on the reaction rate data collected in aprotic solvents (Scheme 8). ${ }^{11}$ They found that the BaylisHillman rate-determining step is second order in aldehyde and first order in DABCO and acrylate. On the basis of these data, they have proposed a new mechanism involving a hemiacetal intermediate (Scheme 8).

\section{Chemical Transformations of BH Adducts}

The Baylis-Hillman adducts are a class of highly functionalized allylic alcohols or allylic amines. In addition, a variety of electron withdrawing substituents can be introduced into the $\mathrm{BH}$ adducts. In these respects, the $\mathrm{BH}$ adducts can be transformed into many acyclic and cyclic compounds including quinolines, indoles, pyrazoles, naphthalenes, indazoles, etc. ${ }^{1}$ In this review, we will deal with the chemical transformations of $\mathrm{BH}$ adducts, categorized into eight parts depending on the key reaction involved.

Nucleophilic aromatic substitution reaction $\left(\mathrm{S}_{\mathrm{N}} \mathrm{Ar}\right)$ in BH chemistry. We have introduced the aromatic nucleo-<smiles>C=CC(=O)OC</smiles><smiles>CO/C([O-])=C/CN1CCN2CCN1CC2</smiles>

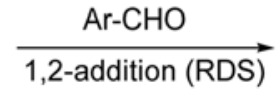<smiles>COC(=O)C(CN1CCN2CCC1CC2)C(=O)OC</smiles><smiles>C=C(C(=O)OC)C(O)Br</smiles>

Scheme 7. Old mechanism of Baylis-Hillman reaction.<smiles>C=CC(=O)OC</smiles><smiles>CO/C([O-])=C/CN1CCN(CCO)CC1</smiles><smiles>O=CC1CCCCC1</smiles><smiles>COC(=O)C(CN1CCN2CCC1CC2)C(=O)OC</smiles><smiles>O=C[Te]</smiles>

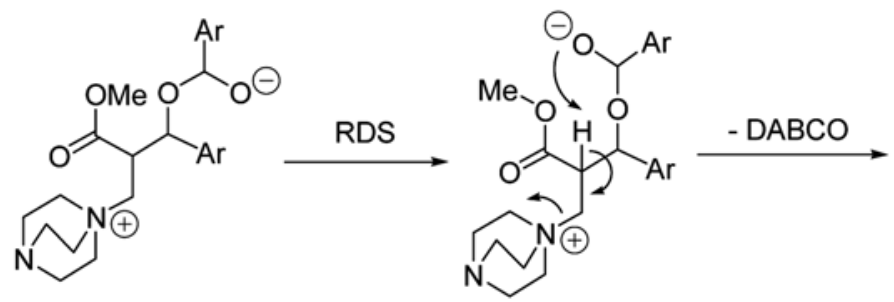<smiles>[B]C[Al]C(OC(O)Br)C(=C)C(=O)OC</smiles>

Scheme 8. New mechanism of Baylis-Hillman reaction.

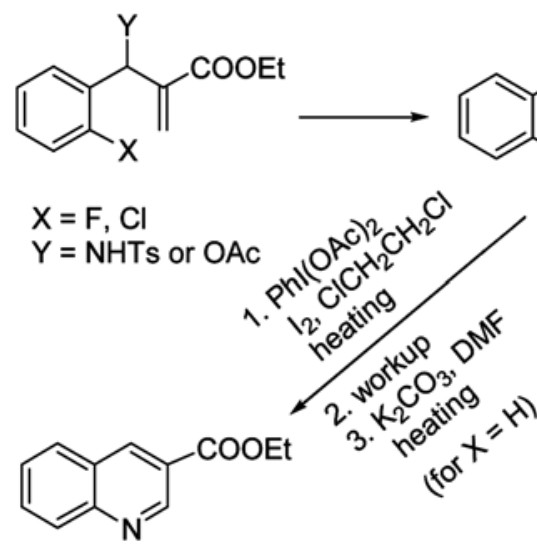<smiles>[X]c1ccccc1/C=C(\CN[Sb])C(=O)OCC</smiles>

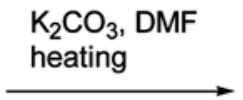<smiles>CCOC(=O)c1cnc2ccccc2c1</smiles><smiles>CCOC(=O)C1=Cc2ccccc2N([125I])C1</smiles><smiles>CCCC</smiles>

Scheme 9. Synthesis of quinoline derivatives. 
philic substitution reaction $\left(\mathrm{S}_{\mathrm{N}} \mathrm{Ar}\right)$ for the first time in the $\mathrm{BH}$ chemistry for the synthesis of quinolines from the $\mathrm{BH}$ adducts of ortho-halo benzaldehydes (Scheme 9). ${ }^{12}$ Later, we extended the usefulness of $\mathrm{S}_{\mathrm{N}} \mathrm{Ar}$ reaction for the synthesis of $N$-substituted 1,4-dihydroquinolines ${ }^{13}$ and 2substituted naphthalenes (Scheme 10). ${ }^{14}$ For the successful synthesis of these compounds, electron withdrawing conjugated ester moiety is crucial, which make the $\mathrm{S}_{\mathrm{N}} \mathrm{Ar}$ reaction more facile. In addition, we have reported the successful synthesis of quinolines and naphthalenes from the $\mathrm{BH}$ adducts derived from benzaldehydes without a orthohalogen substituent via oxidative cyclization strategy using iodobenzene diacetate and manganese (III) acetate, respectively (shown in Schemes 9 and 10). ${ }^{15,16}$

Radical cyclization in BH chemistry. Shanmugam and co-workers have studied extensively on the radical cyclization of the modified BH adducts. ${ }^{17}$ They used radical cyclization strategy for the synthesis of exo-methylene tetrahydrofurans, tetrahydropyrans, and oxepanes (Scheme 11). Recently, we extended the radical cyclization for the synthesis of 2,5-dihydrofurans efficiently (Scheme 12). ${ }^{18} \mathrm{We}$ obtained 2,5-dihydrofurans via the consecutive radical cyclization, halolactonization, and finally spontaneous decarboxylation strategy starting from the $\mathrm{BH}$ adducts having propargyloxy group at the primary position.

Ring-closing metathesis (RCM) reaction in $\mathrm{BH}$ chemistry. The combination of $\mathrm{BH}$ chemistry and RCM methodology was first used for the synthesis of $\alpha$-methylene- $\gamma$-lactones fused to medium and large rings by Paquette group (Scheme 13). ${ }^{19}$ We have studied the synthesis of 2,5-

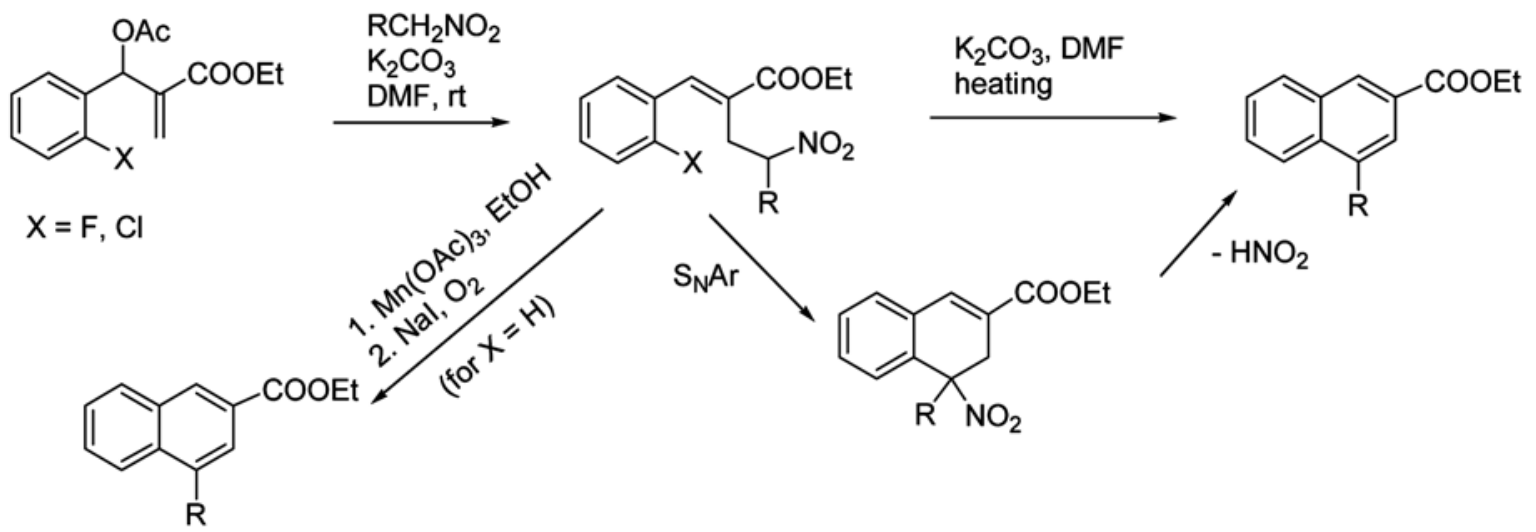

Scheme 10. Synthesis of naphthalene derivatives.
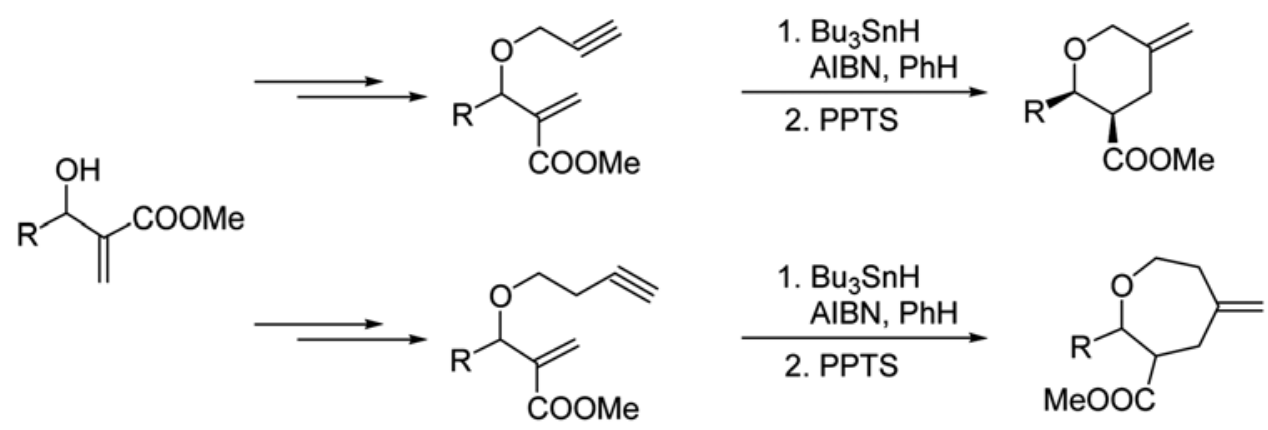

Scheme 11. Radical cyclization of modified BH adducts.<smiles>C=C(C(=O)OC)C(O)c1ccccc1</smiles><smiles>C#CCOc1ccc(O)cc1</smiles><smiles>C#CCOC/C(=C\c1ccccc1)C(=O)OC</smiles>

1. AIBN (cat)
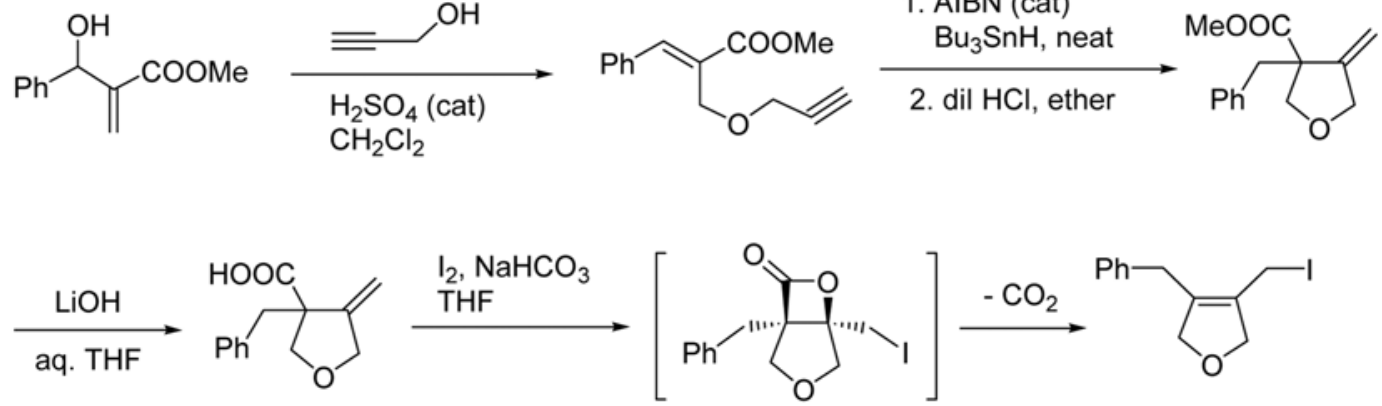<smiles>O=C1OC2COC[C@]12Cc1ccccc1</smiles><smiles>ICC12COCC1OC2I</smiles>

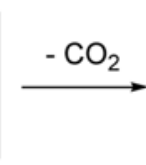<smiles>ICC1=C(Cc2ccccc2)COC1</smiles>

Scheme 12. Synthesis of 2,5-dihydrofurans. 


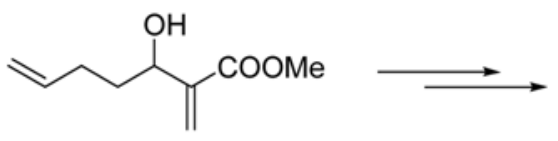<smiles>C=CCCCC(C(=C)C(=O)OC)C(O)CCC=C</smiles><smiles>C=C1C(=O)OC2CC/C=C\CCC12</smiles>

Scheme 13. Synthesis of $\alpha$-methylene- $\gamma$-lactones.

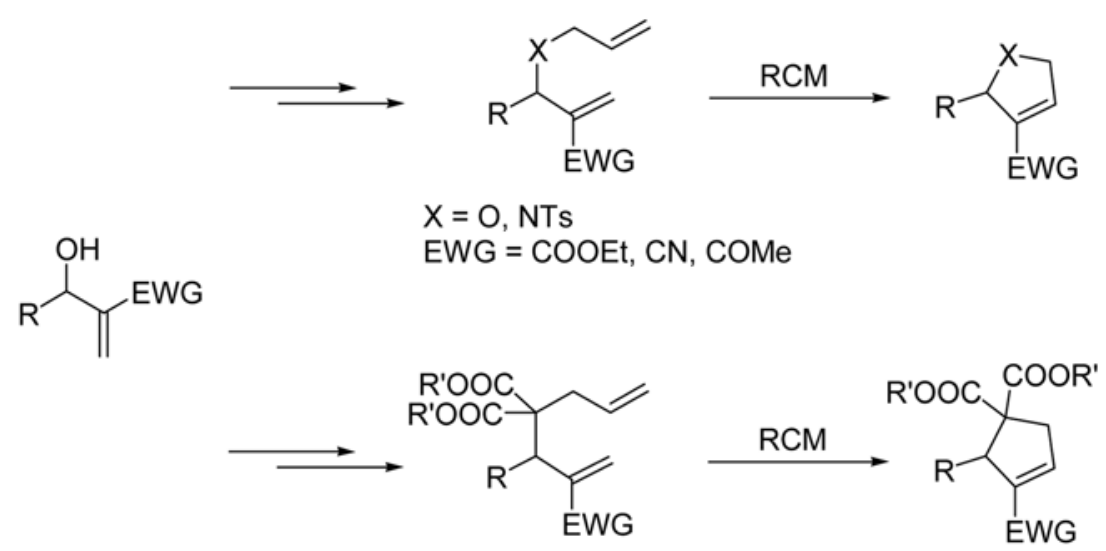

Scheme 14. Synthesis of 2,5-dihydrofurans, 2,5-dihydropyrroles, and cyclopentenes.

dihydrofurans $,{ }^{20 \mathrm{a}} 2,5$-dihydropyrroles, ${ }^{20 \mathrm{a}}$ cyclopentenes, ${ }^{20 \mathrm{~b}}$ and lactones ${ }^{20 \mathrm{c}}$ by using the RCM reaction with appropriately modified $\mathrm{BH}$ adducts (Scheme 14). Lamaty also reported the synthesis of pyrroles by using the RCM reaction from the aza-BH adducts. ${ }^{21 a}$ Many research groups have also used the RCM reaction for the synthesis of natural products from the $\mathrm{BH}$ adducts. ${ }^{21}$ Based on the increasing number of papers in these areas, the applications of RCM reaction on the $\mathrm{BH}$ chemistry will be used more frequently and efficiently for the synthesis of many important compounds including natural products.

Friedel-Crafts reaction in $\mathbf{B H}$ chemistry. Basavaiah used Friedel-Crafts reaction for the first time at the relatively earlier stage of $\mathrm{BH}$ chemistry for the stereoselective synthesis of trisubstituted alkenes. ${ }^{22}$ Later on, we also used
Friedel-Crafts reaction for the synthesis of trisubstituted alkenes from the $\mathrm{BH}$ adducts of $\mathrm{N}$-tosylimines. ${ }^{23}$ FriedelCrafts reaction has also been applied successfully for the synthesis of 3-alkylidenechroman-4-ones, ${ }^{24}$ indene derivatives, ${ }^{25}$ and 2-arylideneindan-1-ones ${ }^{26}$ (Scheme 15). The syntheses of these compounds were straightforward as shown in the Scheme 15 although low yields were obtained in some cases. Interestingly, both inter- and intramolecular Friedel-Crafts reactions were used successively for the synthesis of 2-arylideneindan-1-one derivatives. ${ }^{26 a}$ Recently, we extended the reaction toward intramolecular FriedelCrafts alkenylation reaction with triple bond-tethered $\mathrm{BH}$ adducts for the synthesis of 9-phenyl-7H-benzocycloheptene-6-carboxylate derivatives (Scheme 16). ${ }^{27}$ This is the first intramolecular Friedel-Crafts alkenylation of electron-

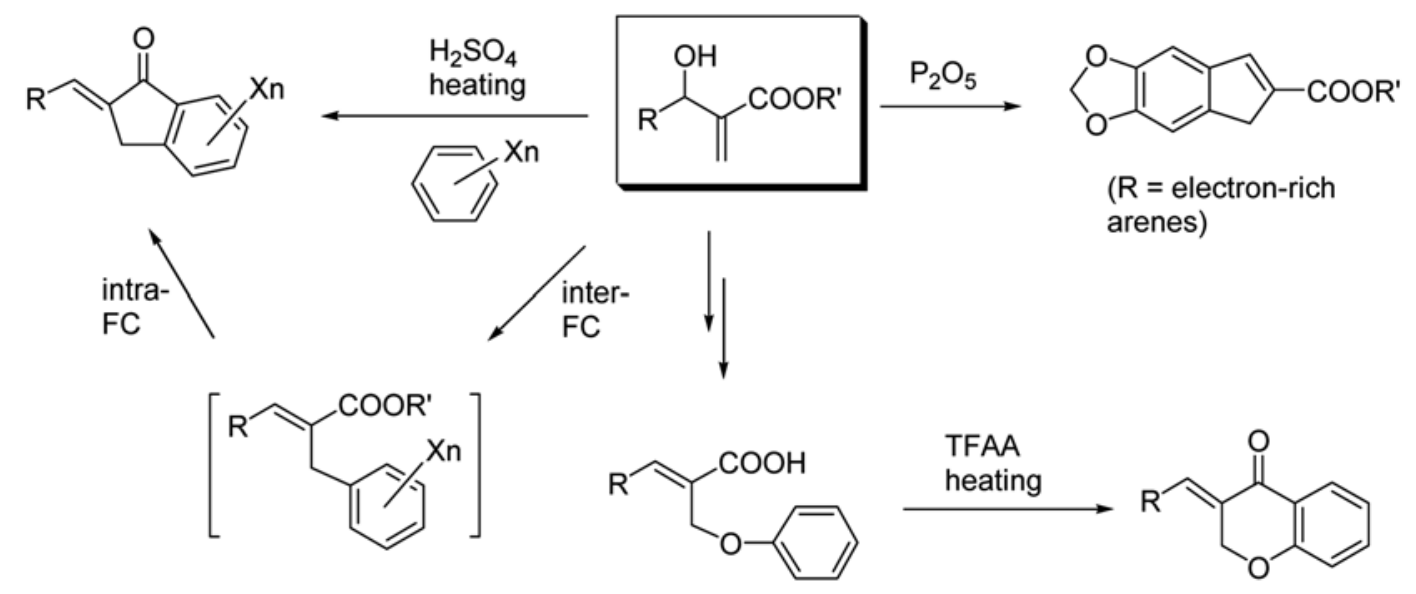

Scheme 15. Friedel-Crafts reaction in Baylis-Hillman chemistry. 
<smiles>C=C(C(C)=O)C(OC(C)=O)c1ccccc1</smiles><smiles>[R]C#CCC(=Cc1ccccc1)C(C)=O</smiles><smiles>[R]C1=CCC(C(C)=O)=Cc2ccccc21</smiles>

Scheme 16. Synthesis of benzocycloheptenes.

deficient arene nucleus for the synthesis of seven-membered ring.

Halolactonization in BH chemistry. We have reported the synthesis and applications of multiple bond-tethered $\mathrm{BH}$ adducts. As an example, we prepared some iodoenol lactone derivatives using typical iodolactonization protocol by using the triple bond-tethered $\mathrm{BH}$ adducts (Scheme 17). ${ }^{28}$ In the reaction, halolactonization proceeded via the 5-exo-dig manner to give the haloenol lactone as the sole product. As mentioned above in the radical cyclizations part, halolactonization was used efficiently for the synthesis of 2,5dihydrofurans in combination with spontaneous decarboxylation reaction (Scheme 12 ). ${ }^{18} \alpha$-Arylidene- $\gamma$-butyrolactones have also been synthesized from the alkenyl moiety-containing BH adducts via sulfuric acid-assisted lactonization (shown in Scheme 17). ${ }^{29}$ It is interesting to note that the initially formed $\gamma$ butyrolactone derivatives could be converted into the corresponding dihydronaphthalenes at elevated temperature under the influence of sulfuric acid via ring-opening followed by Friedel-Crafts reaction.

Claisen rearrangement in $\mathrm{BH}$ chemistry. JohnsonClaisen rearrangement of $\mathrm{BH}$ adducts with triethyl orthoacetate was first examined by Basavaiah group (Scheme
18). ${ }^{30}$ They observed an unprecedented stereochemical reversal from alkyl to aryl substituents in the JohnsonClaisen rearrangement of methyl 3-hydroxy-2-methylenealkanoates with triethyl orthoacetate as shown in Scheme 18. The key backbone of the BH adducts is basically an allylic alcohol or an allylic amine. Thus, introduction of vinyl moiety either at the oxygen or nitrogen atom of the $\mathrm{BH}$ adducts could produce allyl vinyl ether or allyl vinyl amine compounds, which could be transformed further under the appropriate Claisen rearrangement conditions. By using aniline moiety-containing $\mathrm{BH}$ adducts at the secondary position, we have prepared 3-benzylidene-3,4-dihydro- $1 H$ quinoline-2-ones, 4-amino-2-benzylideneindan-1-ones, and 1-amino-9a, 10-dihydro-4b $H$-indeno[1,2- $a$ ] inden-9-one derivatives (Scheme 19). ${ }^{31 a}$ The three types of different compounds were formed depending on the substituents of the aniline moiety via the common intermediate, generated in situ by the $a z a$-Claisen rearrangement. Very recently, we extended the $a z a$-Claisen rearrangement of $\mathrm{BH}$ adducts to the synthesis of polysubstituted quinolines. ${ }^{31 \mathrm{~b}}$

Application of aldol condensation to $\mathrm{BH}$ chemistry. Introduction of activated methylene compounds like as acetylacetone at the primary position of the $\mathrm{BH}$ adducts can be carried out easily by the addition-elimination

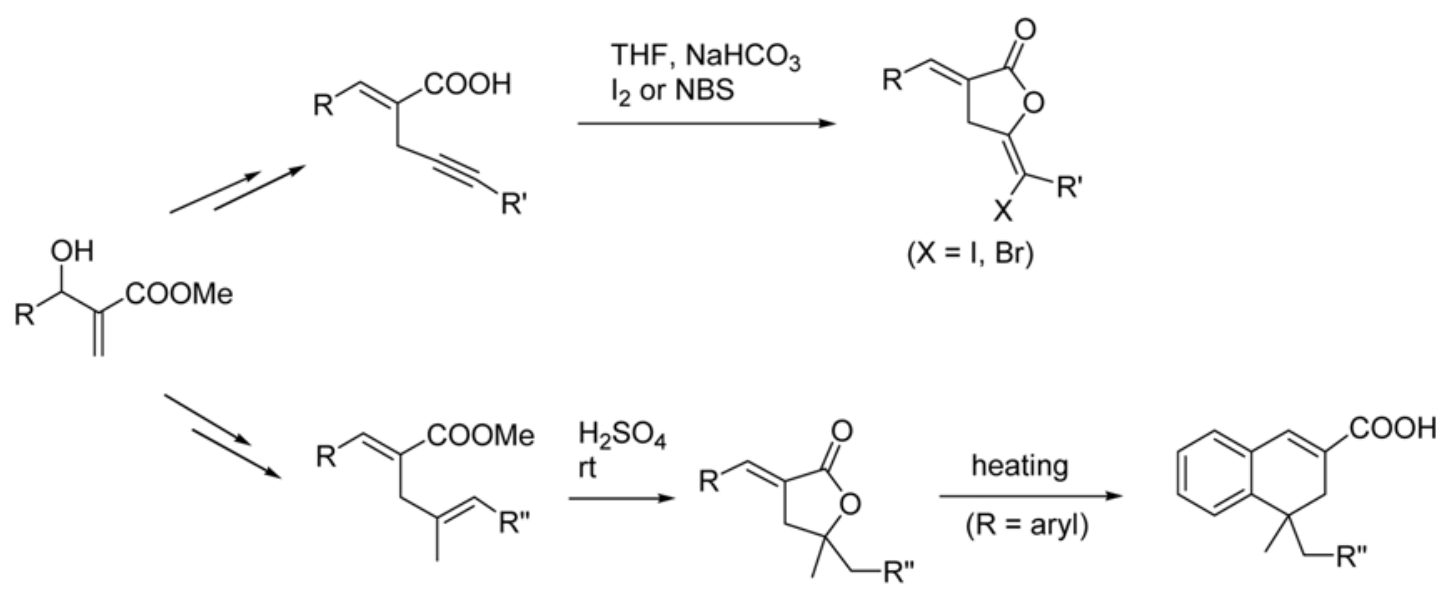

Scheme 17. Cyclization of multiple bond-tethered BH adducts.<smiles>[R]C(O)C(=C)C(=O)OC</smiles>

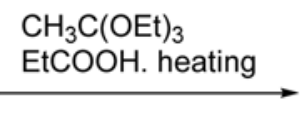

$+$<smiles>[R]C=C(CCC(OC)OCC)COC</smiles>

(major for R = alkyl)

Scheme 18. Claisen rearrangement of $\mathrm{BH}$ adducts. 
sequence from the acetates of the $\mathrm{BH}$ adducts. After introduction of some carbonyl moiety to the $\mathrm{BH}$ adducts, a variety of condensation reactions could be performed between the EWG moiety of the original $\mathrm{BH}$ adducts and the newly introduced carbonyl functionality. Amri applied the aldol reaction in the BH chemistry for the first time
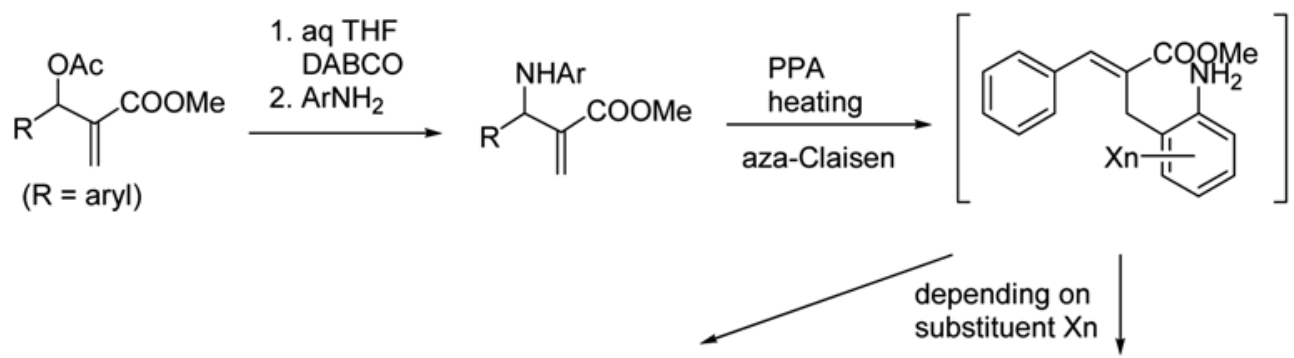

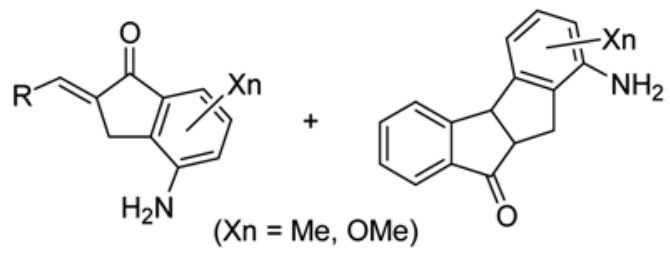

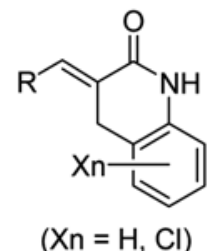

Scheme 19. Synthetic applications of aza-Claisen rearrangement.

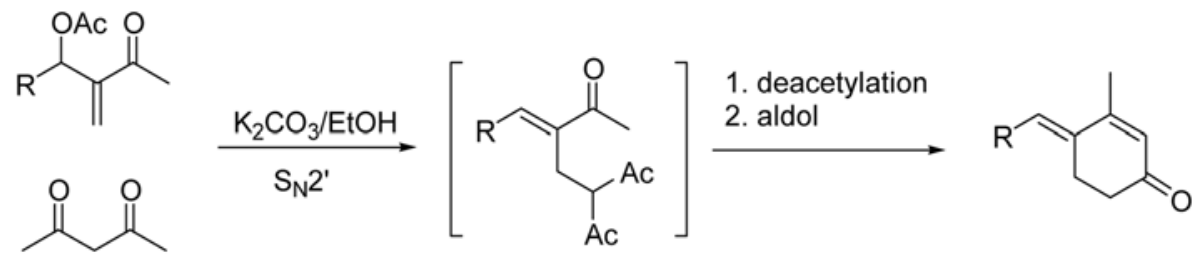

Scheme 20. First application of aldol reaction in BH chemistry.
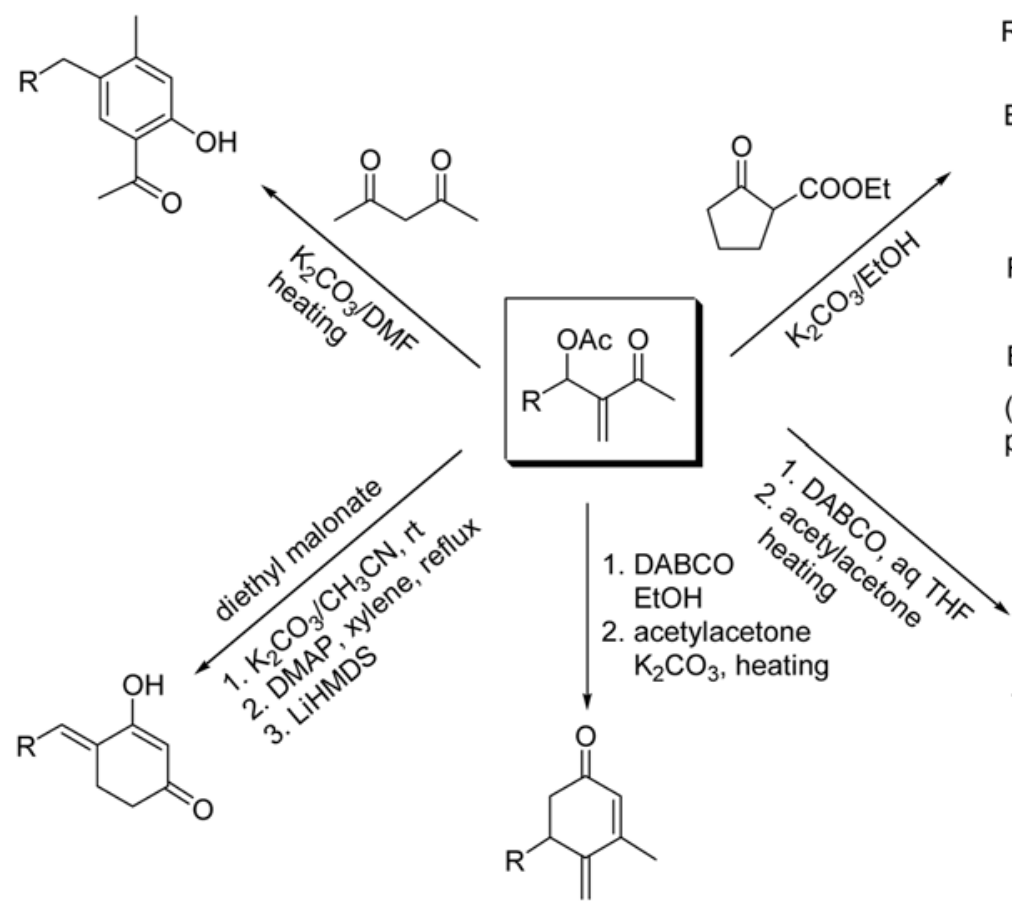

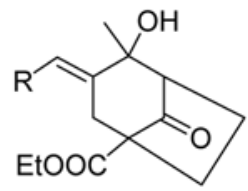

(kinetic product)<smiles>[R]C=C1CC2(O)CCCC2(O)CC1=O</smiles>

(thermodynamic product)<smiles>[R]C1C(C(C)=O)=C(C)OC[C@H]1C(C)=O</smiles>

Scheme 21. Applications of aldol reaction in BH chemistry. 


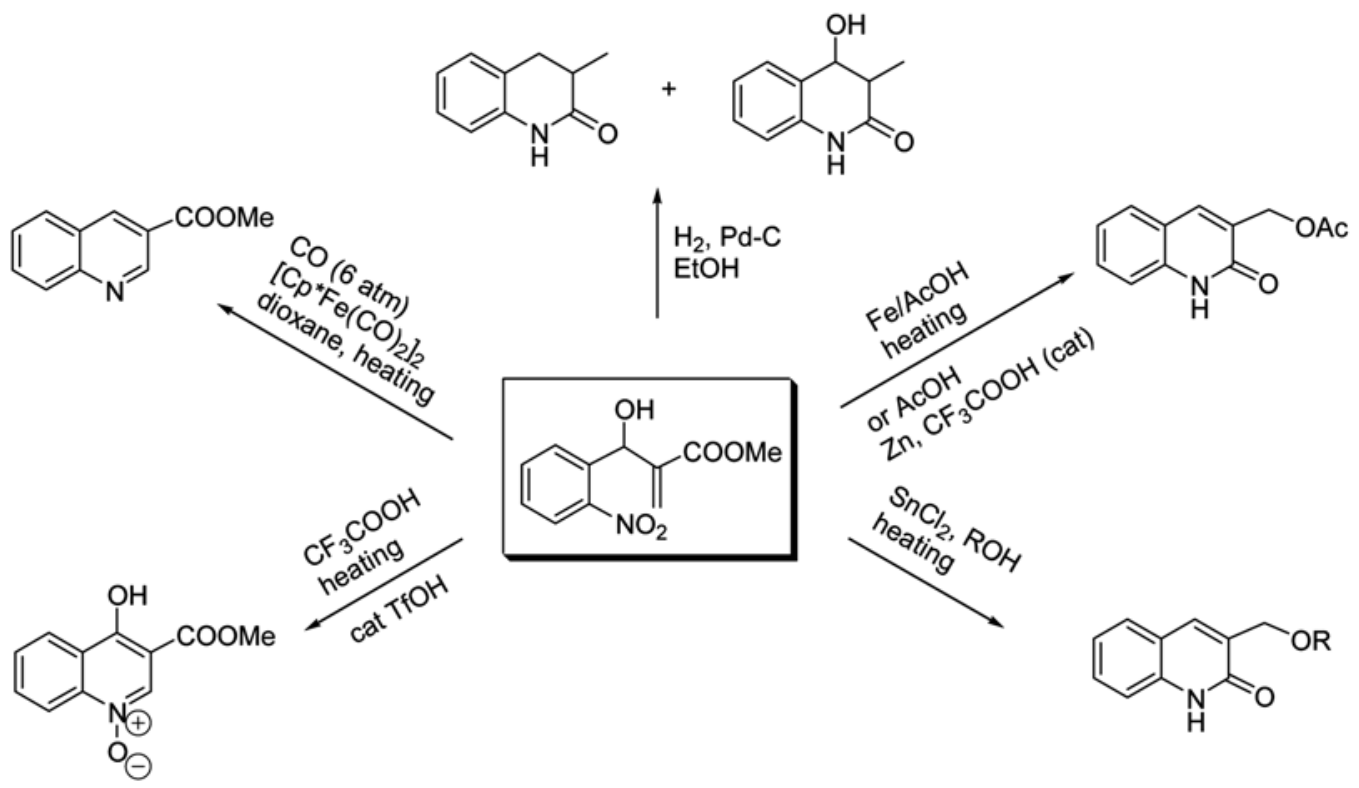

Scheme 22. Reductive cyclization of modified BH adducts.

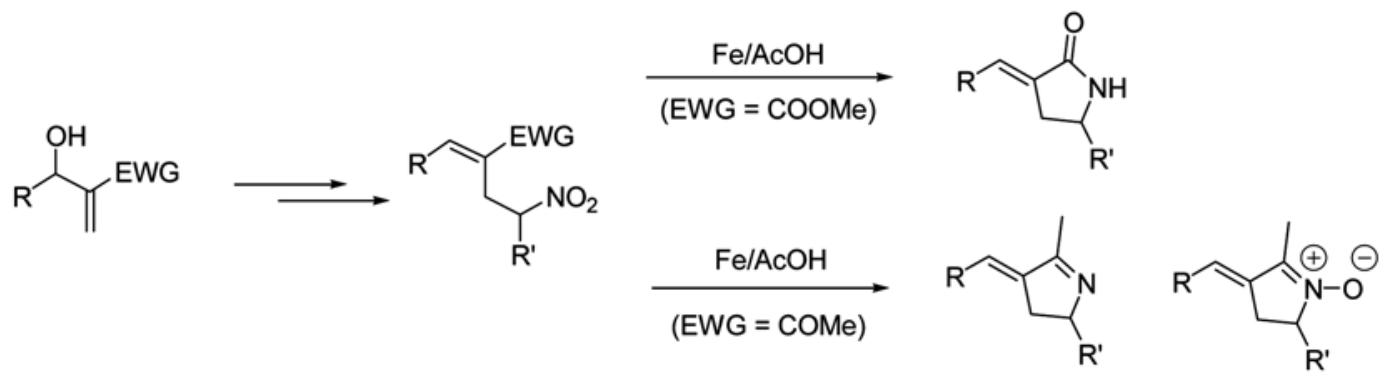

Scheme 23. Reductive cyclization of modified BH adducts.

for their synthesis of 4-alkylidene-2-cyclohexen-1-ones (Scheme 20). ${ }^{32}$ By using similar strategy we have reported the synthesis of ortho-hydroxyacetophenones, ${ }^{33}$ 3-alkylidenebicyclo[3.2.1] octan-8-one derivatives, ${ }^{34}$ 4-arylidenecyclohexane-1,3-diones, ${ }^{35}$ 3,4-dihydro-2 $H$-pyrans, ${ }^{36}$ and 4 methylene-2-cyclohexenones ${ }^{37}$ (Scheme 21). Simply changing the reaction medium to DMF from EtOH in the reaction of acetylacetone and the acetate of the $\mathrm{BH}$ adducts, we could obtain ortho-hydroxyacetophenones instead of Amri's 4-alkylidene-2-cyclohexen-1-one. In DMF, unwanted deacetylation before aldol reaction could be controlled not to occur. ${ }^{33}$ During the introduction of acetylacetone at the secondary position of the $\mathrm{BH}$ acetates by using the DABCO salt strategy in aqueous THF, spontaneous Michael addition occurred via the 6-endo-trig manner to give 3,4dihydro- $2 H$-pyrane derivatives simply by warming the reaction mixtures. ${ }^{36}$ In contrast, we could obtain 4-methylene-2-cyclohexenones from the same starting materials by following the Amri's protocol after the introduction of acetylacetone at the secondary position of $\mathrm{BH}$ adducts in EtOH. $^{37}$

Reductive cyclization in BH chemistry. Reduction of nitro group of $\mathrm{BH}$ adducts either at the ortho-position of the aromatic nucleus (Scheme 22) ${ }^{38}$ or at the side chain (Scheme $23)^{39}$ was used in order prepare some cyclic compounds including quinolines, ${ }^{38 \mathrm{a}, \mathrm{c}-\mathrm{f}}$ acridines, ${ }^{38 \mathrm{~b}}$ and $\gamma$-lactams. ${ }^{39}$ Reductive cyclization of $\mathrm{BH}$ adducts bearing nitro group at the ortho-position of aromatic nucleus was carried out by Kaye and co-workers under catalytic hydrogenation conditions to give quinoline derivatives. ${ }^{38 a}$ Reductive cyclization in the presence of carboxylic acid or alcohol gave 3substituted-2-quinolone derivatives. ${ }^{38 \mathrm{c}-\mathrm{e}}$ We have reported the synthesis of 4-hydroxyquinoline $N$-oxides from the nitro group-containing $\mathrm{BH}$ adducts although the reaction did not involve the use of reducing reagent. ${ }^{40}$ Recently, Basavaiah and Rao reported the facile synthesis of substituted $\gamma$ lactams from the Baylis-Hillman adducts as shown in Scheme 23. ${ }^{39}$ Under the same conditions $(\mathrm{Fe} / \mathrm{AcOH})$ the $\mathrm{BH}$ adducts containing acetyl group converted into pyrroline and its $N$-oxide in a variable ratios. ${ }^{41}$

\section{Conclusions}

As this review illustrates, $\mathrm{BH}$ reaction has tremendous potentials in organic chemistry both in synthetic aspects and in theoretical aspects. However, there are still many 
problems including increase of reaction rate, control of the stereochemistry of BH adducts, and developments of many efficient and useful chemical transformations for the $\mathrm{BH}$ adducts in order to make $\mathrm{BH}$ reaction more important.

Acknowledgments. J. N. Kim wishes to thank to Dr. Eung K. Ryu. Thanks also go to the previous members, Dr. H. J. Lee, J. S. Son, K. S. Jung, M. R. Seong, H. N. Song, H. S. Kim, T. Y. Kim, Y. M. Chung, J. H. Gong, Y. J. Im, J. M. Kim, C. G. Lee, J. E. Na and present members K. Y. Lee, S. Gowrisankar, M. J. Lee, S. C. Kim, and D. Y. Park. We also appreciate to Prof. S. Kim, the chief-editor of $\mathrm{BKCS}$, for the kind invitation of this account.

\section{References and Notes}

1. Some selected review articles, (a) Basavaiah, D.; Rao, A. J.; Satyanarayana, T. Chem. Rev. 2003, 103, 811. (b) Ciganek, E., In Organic Reactions; Paquette, L. A., Ed.; John Wiley \& Sons: New York, 1997; Vol. 51, pp 201-350. (c) Basavaiah, D.; Rao, P. D.; Hyma, R. S. Tetrahedron 1996, 52, 8001. (d) Kim, J. N.; Lee, K. Y. Curr. Org. Chem. 2002, 6, 627.

2. Rauhut, M.; Currier, H. U. S. Patent 3,074,999, 1963; Chem. Abstr. 1963, 58, 11224a.

3. Morita, K.; Suzuki, Z.; Hirose, H. Bull. Chem. Soc. Jpn. 1968, 41, 2815.

4. Baylis, A. B.; Hillman, M. E. D. German Patent 2,155,113, 1972; Chem. Abstr. 1972, 77, 34174q.

5. Some selected papers of Prof. Krische, (a) Jellerichs, B. G.; Kong, J.-R.; Krische, M. J. J. Am. Chem. Soc. 2003, 125, 7758. (b) Wang, L.-C.; Luis, A. L.; Agapiou, K.; Jang, H.-Y.; Krische, M. J. J. Am. Chem. Soc. 2002, 124, 2402. (c) Wang, J.-C.; Ng, S.-S.; Krische, M. J. J. Am. Chem. Soc. 2003, 125, 3682. (d) Luis, A. L.; Krische, M. J. Synthesis 2004, 2579. (e) Cho, C.-W.; Kong, J.-R.; Krische, M. J. Org. Lett. 2004, 6, 1337.

6. Some selected papers of Prof. Roush, (a) Frank, S. A.; Mergott, D. J.; Roush, W. R. J. Am. Chem. Soc. 2002, 124, 2404. (b) Methot, J. L.; Roush, W. R. Adv. Synth. Catal. 2004, 346, 1035. (c) Methot, J. L.; Roush, W. R. Org. Lett. 2003, 5, 4223. (d) Mergott, D. J.; Frank, S. A.; Roush, W. R. Org. Lett. 2002, 4, 3157.

7. (a) Roth, F.; Gygax, P.; Frater, G. Tetrahedron Lett. 1992, 33, 1045. (b) Dinon, F.; Richards, E.; Murphy, P. J.; Hibbs, D. E.; Hursthouse, M. B.; Malik, K. M. A. Tetrahedron Lett. 1999, 40, 3279. (c) Richards, E.; Murphy, P. J.; Dinon, F.; Fratucello, S.; Brown, P. M.; Gelbrich, T.; Hursthouse, M. B. Tetrahedron 2001, 57, 7771. (d) Brown, P. M.; Kappel, N.; Murphy, P. J. Tetrahedron Lett. 2002, 43, 8707. (e) Yeo, J. E.; Yang, X.; Kim, H. J.; Koo, S. Chem. Commun. 2004, 236.

8. Gong, J. H.; Im, Y. J.; Lee, K. Y.; Kim, J. N. Tetrahedron Lett. 2002, 43, 1247 and references cited therein for the Stetter reaction.

9. Hoffmann, H. M. R.; Rabe, J. Angew. Chem. Int. Ed. Engl. 1983, 22,795 .

10. (a) Hill, J. S.; Isaacs, N. S. Tetrahedron Lett. 1986, 27, 5007. (b) Hill, J. S.; Isaacs, N. S. J. Phys. Org. Chem. 1990, 3, 285.

11. (a) Price, K. E.; Broadwater, S. J.; Jung, H. M.; McQuade, D. T. Org. Lett. 2005, 7, 147. (b) Price, K. E.; Broadwater, S. J.; Walker, B. J.; McQuade, D. T. J. Org. Chem. 2005, 70, 3980.

12. (a) Kim, J. N.; Lee, H. J.; Lee, K. Y.; Kim, H. S. Tetrahedron Lett. 2001, 42, 3737. (b) Chung, Y. M.; Lee, H. J.; Hwang, S. S.; Kim, J. N. Bull. Korean Chem. Soc. 2001, 22, 799.
13. Kim, J. N.; Kim, H. S.; Gong, J. H.; Chung, Y. M. Tetrahedron Lett. 2001, 42, 8341.

14. (a) Kim, J. N.; Im, Y. J.; Gong, J. H.; Lee, K. Y. Tetrahedron Lett. 2001, 42, 4195. (b) Im, Y. J.; Chung, Y. M.; Gong, J. H.; Kim, J. N. Bull. Korean Chem. Soc. 2002, 23, 787.

15. Kim, J. N.; Chung, Y. M.; Im, Y. J. Tetrahedron Lett. 2002, 43, 6209.

16. Im, Y. J.; Lee, K. Y.; Kim, T. H.; Kim, J. N. Tetrahedron Lett. 2002, 43, 4675 .

17. (a) Shanmugam, P.; Rajasingh, P. Tetrahedron 2004, 60, 9283. (b) Shanmugam, P.; Rajasingh, P. Chem. Lett. 2002, 1212. (c) Shanmugam, P.; Rajasingh, P. Synlett 2005, 939. (d) Shanmugam, P.; Rajasingh, P. Tetrahedron Lett. 2005, 46, 3369.

18. Gowrisankar, S.; Lee, K. Y.; Kim, J. N. Tetrahedron Lett. 2005, 46, 4859.

19. Paquette, L. A.; Mendez-Andino, J. Tetrahedron Lett. 1999, 40, 4301.

20. (a) Kim, J. M.; Lee, K. Y.; Lee, S.; Kim, J. N. Tetrahedron Lett. 2004, 45, 2805. (b) Lee, K. Y.; Na, J. E.; Lee, J. Y.; Kim, J. N. Bull. Korean Chem. Soc. 2004, 25, 1280. (c) Lee, M. J.; Lee, K. Y.; Lee, J. Y.; Kim, J. N. Org. Lett. 2004, 6, 3313.

21. (a) Declerck, V.; Ribiere, P.; Martinez, J.; Lamaty, F. J. Org. Chem. 2004, 69, 8372. (b) Krishna, P. R.; Narsingam, M.; Kannan, V. Tetrahedron Lett. 2004, 45, 4773. (c) Anand, R. V.; Baktharaman, S.; Singh, V. K. Tetrahedron Lett. 2002, 43, 5393.

22. (a) Basavaiah, D.; Pandiaraju, S.; Padmaja, K. Synlett 1996, 393. (b) Basavaiah, D.; Krishnamacharyulu, M.; Suguna Hyma, R.; Pandiaraju, S. Tetrahedron Lett. 1997, 38, 2141.

23. Lee, H. J.; Seong, M. R.; Kim, J. N. Tetrahedron Lett. 1998, 39, 6223.

24. Basavaiah, D.; Bakthadoss, M.; Pandiaraju, S. Chem. Commun. 1998, 1639.

25. Basavaiah, D.; Bakthadoss, M.; Jayapal Reddy, G. Synthesis 2001, 919.

26. (a) Lee, H. J.; Kim, T. H.; Kim, J. N. Bull. Korean Chem. Soc. 2001，22，1063. (b) Basavaiah, D.; Mallikarjuna Reddy, R Tetrahedron Lett. 2001, 42, 3025.

27. Gowrisankar, S.; Lee, K. Y.; Lee, C. G.; Kim, J. N. Tetrahedron Lett. 2004, 45, 6141.

28. Gowrisankar, S.; Lee, M. J.; Lee, S.; Kim, J. N. Bull. Korean Chem. Soc. 2004, 25, 1963.

29. Gowrisankar, S.; Lee, C. G.; Kim, J. N. Tetrahedron Lett. 2004, $45,6949$.

30. Basavaiah, D.; Pandiaraju, S.; Krishnamacharyulu, M. Synlett 1996, 747

31. (a) Lee, C. G.; Lee, K. Y.; Lee, S.; Kim, J. N. Tetrahedron 2005 , 61, 1493. (b) Kim, S. C.; Gowrisankar, S.; Kim, J. N. Bull. Korean Chem. Soc. 2005, 26, 1001

32. (a) Chamakh, A.; Amri, H. Tetrahedron Lett. 1998, 39, 375. (b) Chamakh, A.; M'hirsi, M.; Villieras, J.; Lebreton, J.; Amri, H. Synthesis 2000, 295.

33. Kim, J. N.; Im, Y. J.; Kim, J. M. Tetrahedron Lett. 2002, 43, 6597.

34. Kim, J. N.; Kim, J. M.; Lee, K. Y. Synlett 2003, 821.

35. Im, Y. J.; Lee, C. G.; Kim, H. R.; Kim, J. N. Tetrahedron Lett. 2003, 44, 2987.

36. Kim, J. N.; Kim, J. M.; Lee, K. Y.; Gowrisankar, S. Bull. Korean Chem. Soc. 2004, 25, 1733.

37. Kim, J. M.; Lee, K. Y.; Kim, J. N. Bull. Korean Chem. Soc. 2004, 25,328 .

38. (a) Familoni, O. B.; Kaye, P. T.; Klass, P. J. Chem. Commun. 1998, 2563. (b) Basavaiah, D.; Rao, J. S.; Reddy, R. J. J. Org. Chem. 2004, 69, 7379. (c) Lee, K. Y.; Kim, J. M.; Kim, J. N. Bull. Korean Chem. Soc. 2002, 23, 1493 . (d) Lee, K. Y.; Kim, J. N. 
Bull. Korean Chem. Soc. 2002, 23, 939. (e) Basavaiah, D.; Mallikarjuna Reddy, R. M.; Kumaragurubaran, N.; Sharada, D. S. Tetrahedron 2002, 58, 3693. (f) O'Dell, D. K.; Nicholas, K. M. J. Org. Chem. 2003, 68, 6427.

39. Basavaiah, D.; Rao, J. S. Tetrahedron Lett. 2004, 45, 1621.
40. (a) Lee, K. Y.; Kim, J. M.; Kim, J. N. Tetrahedron 2003, 59, 385. (b) Kim, J. N.; Lee, K. Y.; Kim, H. S.; Kim, T. Y. Org. Lett. 2000, 2,343 .

41. Lee, M. J.; Lee, K. Y.; Park, D. Y.; Kim, J. N. Bull. Korean Chem. Soc. 2005, 26, 1281. 